\title{
Experimental study of the hydro-mechanical behaviour of unsaturated argillaceous rocks
}

\author{
Jairo Martin Espitia ${ }^{1,2, a}$, Bernardo Caicedo ${ }^{1}$ and Luis Vallejo ${ }^{3}$ \\ ${ }^{1}$ Department of Civil Engineering, Universidad de Los Andes, Bogotá, Colombia \\ ${ }^{2}$ Mining engineering department, Universidad Pedagógica y Tecnológica de Colombia, Sogamoso, Colombia \\ ${ }^{3}$ Department of Civil \& Environmental Engineering, University of Pittsburgh, Pittsburgh, United States.
}

\begin{abstract}
The aim of this paper is to study the influence of total suction on some physical/mechanical properties related to argillaceous rocks from the Colombian Andes. A wetting path was applied to the rocks using the vapor transfer technique with continuous recording of mass and deformations. Uniaxial compression tests were conducted on specimens at different levels of suction. In addition, microstructural observations are carried out using a Mercury Intrusion Porosimeter Apparatus. Results from the laboratory tests indicate that anisotropic deformations took place during the wetting path. Also, total suction contributed to a considerable and non-linear reduction in the compressional wave velocity, peak compressive stress, and elastic modulus of the tested samples. Microstructural analysis indicated the influence of the size and number of the pores in the samples on their high levels of suction.
\end{abstract}

\section{Introduction}

A substantial portion of rocks forming part of the earth's crust are argillaceous nature and are usually present in many mining and infrastructure projects[1]. For example, in Colombia a significant part of the population, infrastructure and mining projects are located in the eastern Andes mountain range. In this area, some argillaceous rocks outcrop causing significant challenges for the stability of rock excavations. Indeed, the mineralogical composition of this material makes it sensitive to environmental conditions, such as variation in water content [2]. Furthermore, its mechanical behaviour is the result of the combination of sedimentation, gravitational compaction (consolidation), uplift/unloading (overconsolidation) and cementation/bonding [3].

The hydro-mechanical behaviour of argillaceous rocks has been studied recently using the vapor transfer technique [4-6]. Some features of the behavior of this material in unsaturated conditions can be highlighted as follows: (I) during the application of hydric cycles (without mechanical loading) it is observed hysteresis in the water retention curve, anisotropic deformations and permanent volumetric strains in the material; (II) elastic properties and strength are controlled by the hydric state and the hydric history of the material; (III) the material is degraded as a consequence of hydric cycles.

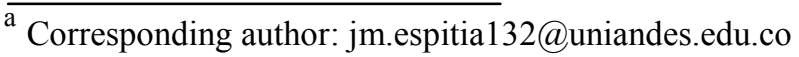

These studies have focused on evaluating the hydromechanical behavior of rocks from geologic formations of Europe. Nonetheless, only a few experimental studies have been performed on South American argillaceous rocks.

Thus, the aim of this paper is to study the hydromechanical behaviour of an argillaceous rock from the eastern Andes mountain range in Colombia in an attempt to establish relations between total suction and some mechanical properties of the material.

\section{Materials and methods}

\subsection{Material}

The material studied is a lower Hauterivian Barremian argillaceous rock, which is an indurated argillite that has caused stability problems in surface and underground rock excavations in some areas of the eastern Andes mountain range. Rock samples were taken from a limestone quarry of the Holcim Company located in Nobsa (Colombia). The average mineralogical composition of this rock is: $53.2 \%$ kaolinite and illite, $29.0 \%$ calcite, $11.0 \%$ quartz, $4.0 \%$ opaque minerals $4.0 \%$ and $1.0 \%$ Muscovite [7]. Table 1 summarizes some properties of the rock. 
Table 1. Index properties of the argillaceous rock [7].

\begin{tabular}{|c|c|}
\hline Property & Value \\
\hline Bulk density & $2570 \mathrm{~kg} / \mathrm{m}^{3}$ \\
\hline $\begin{array}{c}\text { Specific } \\
\text { gravity }\end{array}$ & 2.76 \\
\hline $\begin{array}{c}\text { Water } \\
\text { content }\end{array}$ & $1.50 \%$ \\
\hline Liquid limit & 25 \\
\hline Plastic limit & 15 \\
\hline
\end{tabular}

Irregular block rock samples were taken from a slope at depths greater than $0.5 \mathrm{~m}$. A detailed description of handling and specimen preparation is described in [8]. Specimens, of $20 \mathrm{~mm}$ in diameter and $40 \mathrm{~mm}$ in height perpendicular to bedding plane, were bored with air pressure in order to minimize alteration caused by liquid water. The dimensions of the specimens were chosen in order to minimize the time needed to achieve moisture equilibrium within a controlled humidity atmosphere. Samples tested were obtained from three rock blocks (rock block 1-B1, rock block 10-B10 and rock block 17B17).

The water retention curve (WRC) under unconfined conditions was determined using a chilled-mirror dewpoint psychrometer [9]. The drying path was obtained by setting the rock specimen in a silica gel environment while vapor transfer technique using distilled water was applied for obtaining the wetting path. Figure 1 shows the WRC along a drying-wetting-drying cycle of the undisturbed rock. The WRC exhibits hysteresis during the cycle.

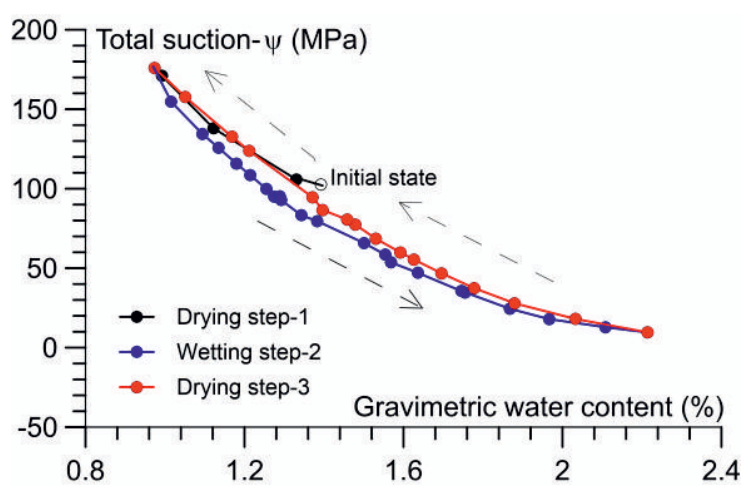

Figure 1. Water retention curve.

Figure 2 illustrates an SEM micrograph of the undisturbed material (perpendicular to the bedding). This figure shows the laminar structure of the material.

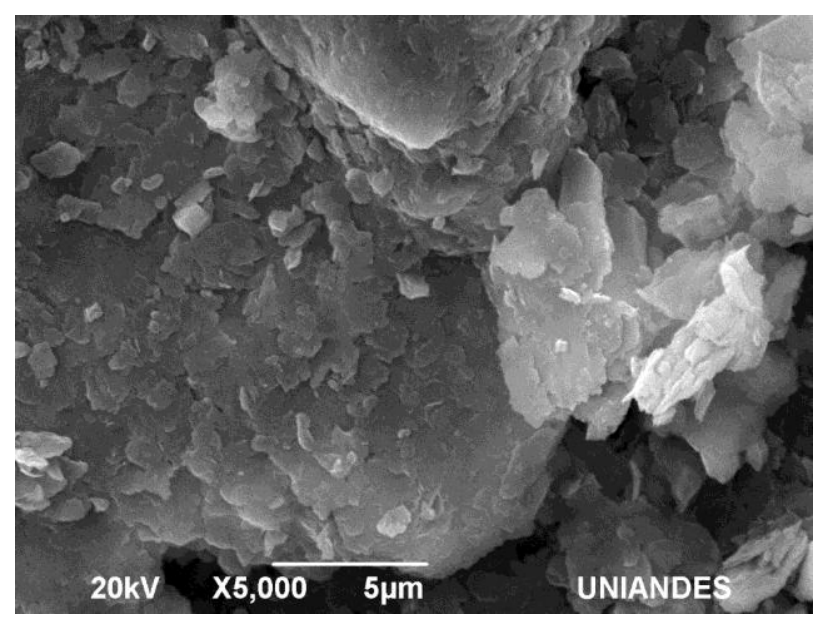

Figure 2. SEM micrograph of the undisturbed material

\subsection{Suction control}

Suction was controlled using vapor transfer technique. This technique is implemented by controlling the relative humidity in a sealed system [10]. The experimental program consisted of the application of a wetting path to the rock specimens. For this, the cylindrical specimens were set in a hermetic acrylic box in which saline solutions imposed relative humidity $(\mathrm{RH})$. We select five saline solutions to cover a range of relative humidity between $33 \%$ and $95 \%$. The values of relative humidity and their corresponding suction are given in Table 2.

During the wetting path, mass, relative humidity, and temperature were recorded. We also measured axial and radial deformations using strain gauges glued to the specimens. At the end of each hydric state, compressional wave velocity was measured on one specimen. During the measuring period, the temperature stayed approximately constant at $22.9 \pm 1.0^{\circ} \mathrm{C}$.

Table 2. Saline solutions used.

\begin{tabular}{|c|c|c|}
\hline $\begin{array}{c}\text { Saline } \\
\text { solution }\end{array}$ & $\begin{array}{c}\text { Relative } \\
\text { humidity (\%) }\end{array}$ & $\begin{array}{c}\text { Suction } \\
\text { (MPa) }\end{array}$ \\
\hline $\mathrm{CaCl}_{2} \cdot 6 \mathrm{H}_{2} \mathrm{O}$ & 33 & 151 \\
\hline $\mathrm{K}_{2} \mathrm{CO}_{3} \cdot 2 \mathrm{H}_{2} \mathrm{O}$ & 47 & 102 \\
\hline $\mathrm{NaBr} \cdot 2 \mathrm{H}_{2} \mathrm{O}$ & 57 & 78 \\
\hline $\mathrm{NaCl}$ & 72 & 46 \\
\hline $\mathrm{K}_{2} \mathrm{SO} 4$ & 95 & 7 \\
\hline
\end{tabular}

The wetting path was imposed on a group of 15 specimens from $\mathrm{B} 1, \mathrm{~B} 10$ and $\mathrm{B} 17$ rock blocks. The moisture equilibrium of the rock specimens in the controlled humidity atmosphere was assumed when weight and strains were stabilized. In general, after eight days the stabilization was reached. Once specimens reached equilibrium, mechanical tests were performed on three specimens of each rock block (Figure 3). 


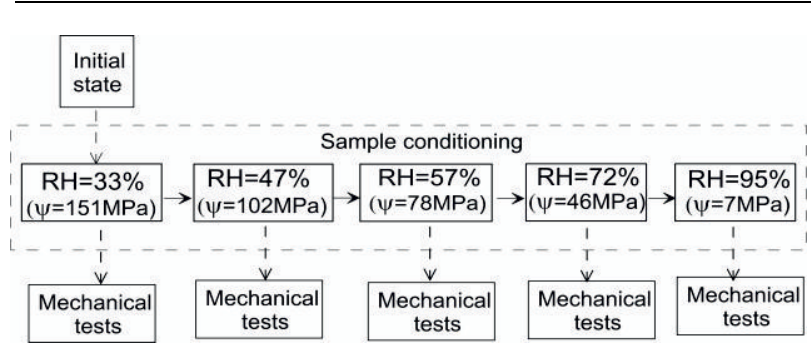

Figure 3. Specimen conditioning experiment.

\subsection{Mechanical tests}

Uniaxial compression tests were conducted on conditioned specimens in a controlled displacement load frame. The axial displacement rate was $0.1 \mathrm{~mm} / \mathrm{min}$. Strain gauges were fixed to measure the local strains in the axial and radial axis directions. The rock moisture was assumed to remain constant during the test due to their short duration (20 $\mathrm{min})$.

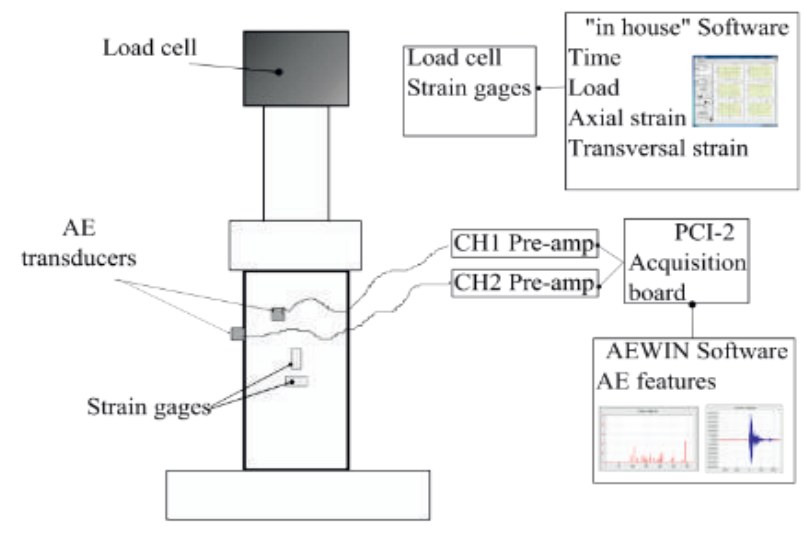

Figure 4. Experimental setup.

\section{Experimental results}

The purpose of the experimental tests was to obtain a better understanding of the hydromechanical behaviour of some argillaceous rocks from the Colombian Andes mountains. In order to achieve this goal, a wetting path was imposed on the rock specimens using the vapor equilibrium technique.

\subsection{Evolution of parameters during the wetting path without mechanical loading}

In this section, we present the evolution of some parameters during the wetting path imposed without mechanical loading. Figure 5 displays the evolution of relative humidity, mass variation, axial and radial strains.

The dimensions of the sealed box provide a ratio between the volume air in the system and the free surface area of the saline solution lower than $25 \mathrm{~cm}^{3} / \mathrm{cm}^{2}$, according to the suggestion in ASTM E 104-02 [11]. According to Figure 5a, the condition of relative humidity for each hydric step was achieved shortly after three days and remained approximately constant after that.
In general, specimens attained stabilization in mass and deformations after eight days (see Figure 5b. and 5c.). In similar studies $[4,5]$, for specimens of $33 \mathrm{~mm}$ in diameter and $76 \mathrm{~mm}$ in height the equilibrium took longer time (approximately 18 days). Therefore, the dimension of the specimens adopted for this study (20 $\mathrm{mm}$ in diameter and $40 \mathrm{~mm}$ in height) allowed a significant reduction of the equilibrium time. Figure 5 (b) indicates that the main mass variation occurred in the last two hydric states (RH 72\% and RH 95\%). Thus, it is reasonable to suppose that the principal changes will occur at these hydric stages.

Regarding deformations due to swelling, Figure 5(c) indicates anisotropy strains in the material. Also, the rock experience the majority of deformations at the same hydric states indicated for mass variation. Figure 6 represents the axial and radial strains at equilibrium for each suction value. An analysis of Fig. 6 shows a nonlinear behaviour and a ratio that ranges from 2.5 to 3 between axial and radial strains.
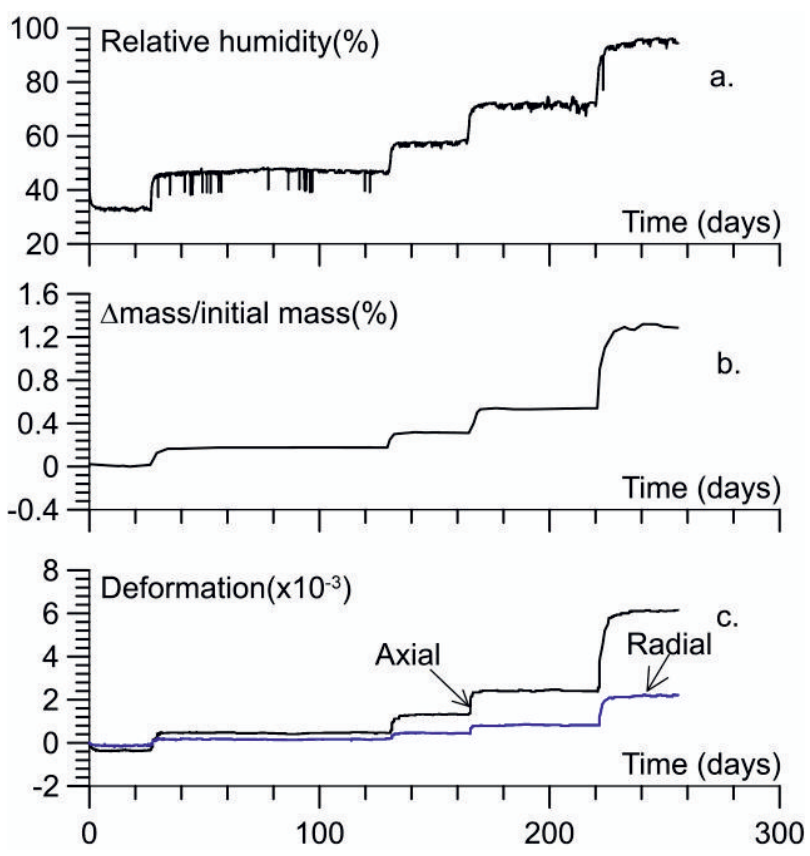

Figure 5. Parameters evolution versus time. (a) Relative humidity. (b) Mass variation. (c) Strains.

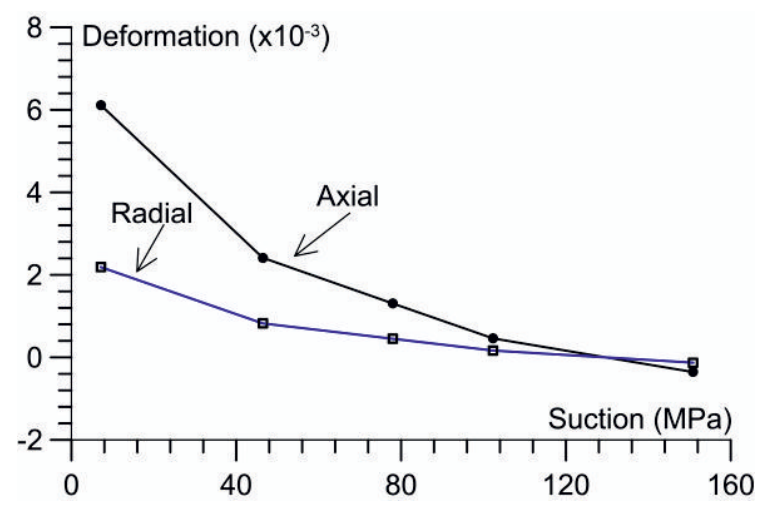

Figure 6. Strains evolution versus suction. 
We measure the compressional wave velocity $(\mathrm{Vp})$ at the end of each hydric state on the same specimen. The variation of compressional wave velocity versus suction is given in Figure 7. We observe from Figure 7 a reduction in $\mathrm{Vp}$ of $25 \%$ from high suction (151 MPa) to low suction $(7 \mathrm{MPa})$ and a non-linear relationship. However, this reduction occurs mainly at the first hydric step (from $151 \mathrm{MPa}$ to $102 \mathrm{MPa}$ ).

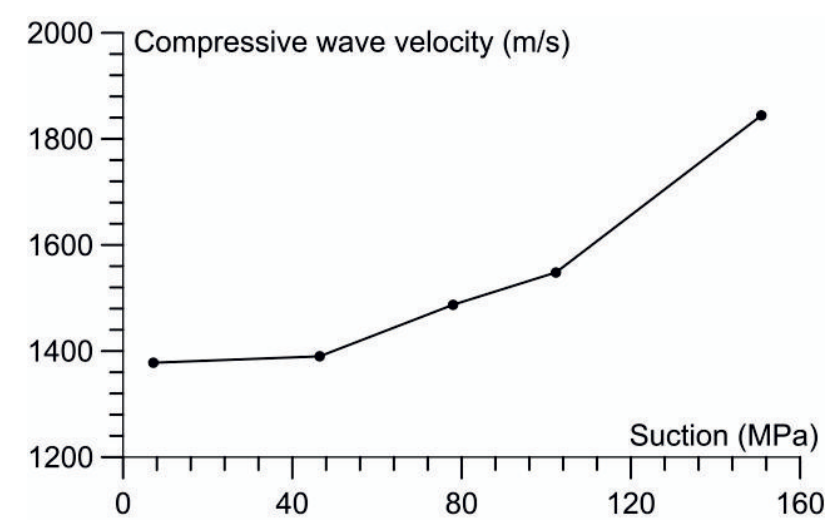

Figure 7. Variation of compressional wave velocity versus suction.

\subsection{Uniaxial compression tests}

In this section, we report data from the uniaxial compression tests carried out on 15 specimens ( 3 for each hydric state and from B1, B10, and B17 rock blocks). We execute the test with the mechanical load perpendicular to the bedding. Figure 8 shows the stressstrain curves of the wetting path of specimens from rock block B1.

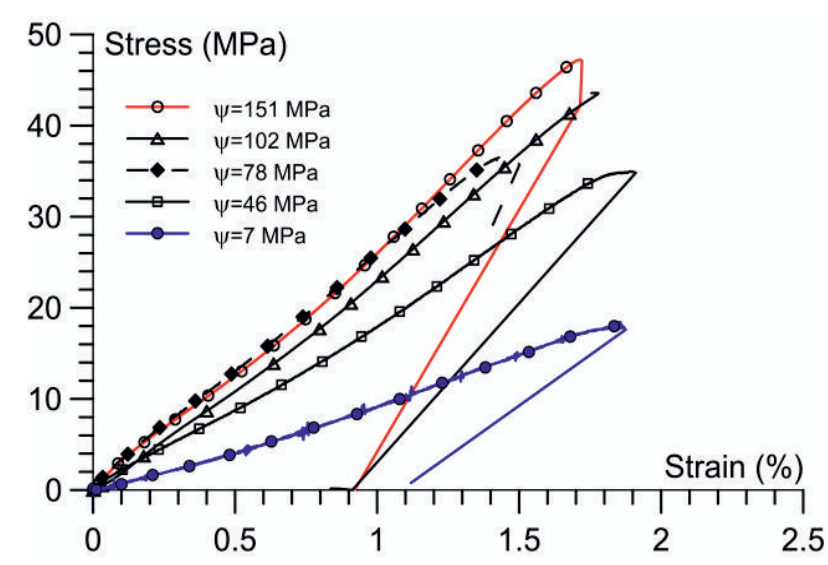

Figure 8. Stress-strain curves for rock block 1 (B1).

Figure 9 contains the peak stress versus suction for all of the tested specimens. A significant reduction in the peak stress can be identified. Comparing the peak stress for the higher $(151 \mathrm{MPa})$ and lower suction $(7 \mathrm{MPa})$, reduction of $61 \%, 58 \%$, and $67 \%$ are obtained for $\mathrm{B} 1$, $\mathrm{B} 10$ and $\mathrm{B} 17$ respectively. It is important to notice that this reduction occurs with a small variation in the water content of the material, from $1 \%$ for the driest condition to $2.3 \%$ for the wettest condition (see Figure 1). Therefore, in the context of rock excavations in this material, the considerations of this features are essential to conceive safer designs. Besides, more than $70 \%$ of the uniaxial compressive strength reduction is observed for the last hydric state as expected. An additional observation is a non-linear relation between peak stress and suction.

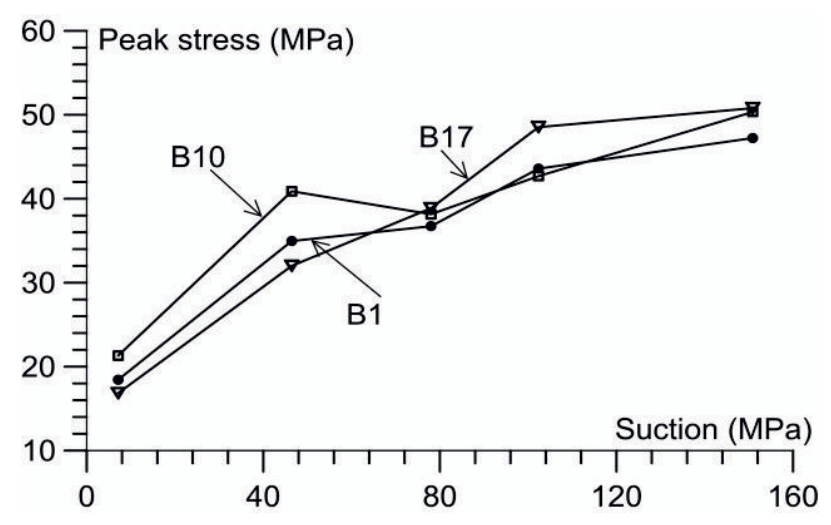

Figure 9. Variation of peak stresses versus suction.

We apply the moving point regression technique to improve the analysis of strain gage data. This procedure utilizes a "sliding window" approach to moving through an $\mathrm{x}$, y data set, fitting a straight line over a user-defined interval. The slope at each point is calculated over the interval and recorded, the process being repeated at successive points [12]. We calculate the slope for each point considering an interval of twenty values, ten before and ten after the point of calculation. Figure 10 presents for rock block B1 the average axial stiffness versus stress for different suction levels. In general, a decrement in the mean axial stiffness with the reduction of suction can be noticed.

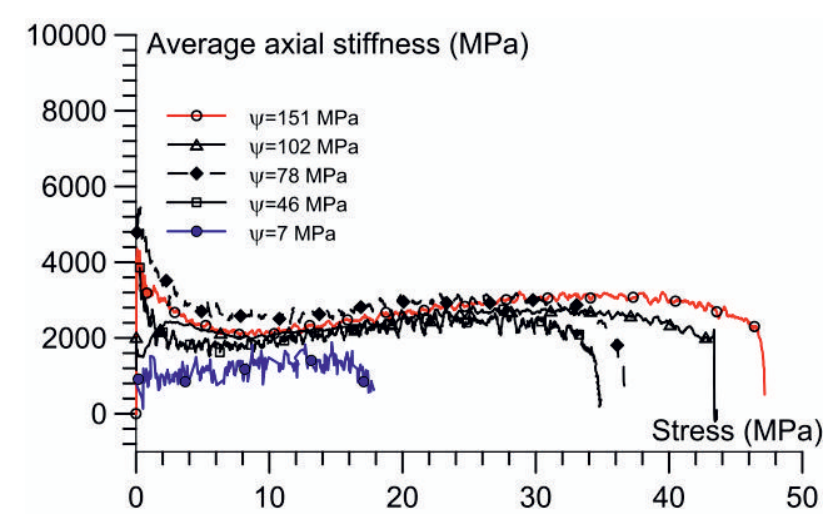

Figure 10. Average axial stiffness versus stress for rock block 1 (B1).

From Figure 10 for each suction value, we identify the portion where the average axial stiffness is almost constant and select it as a representative value of the elastic modulus. This procedure is carried out to obtain a global understanding of the variation of the elastic modulus with suction for all specimens.

Accordingly, Figure 11 summarizes the values of elastic modulus versus suction. Some data dispersion could be noticed from this Figure for suction values of 
$77 \mathrm{MPa}$ and $102 \mathrm{MPa}$. Despite this, a general non-linear decrease in the elastic modulus can be observed in Figure 11. For the extreme conditions of suction, elastic modulus decreases $58 \%, 49 \%$ and $35 \%$ for B1, B10 and B17 rock blocks. Further, more than $78 \%$ of the elastic modulus reduction occurs for the last hydric state as expected.

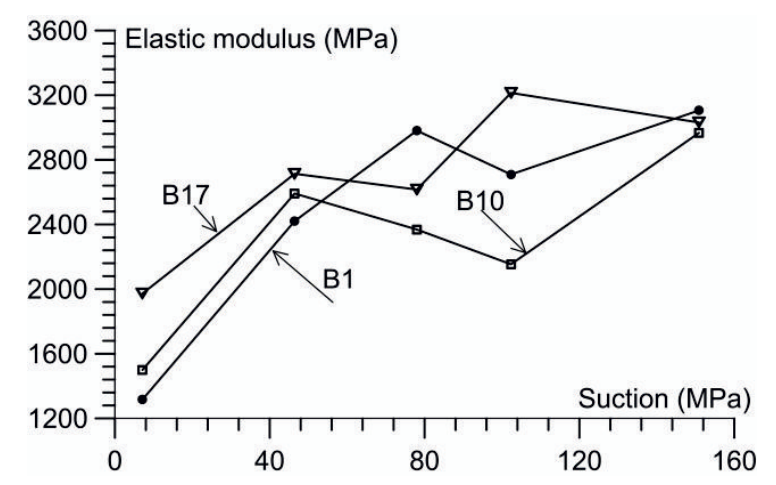

Figure 11. Variation of elastic modulus versus suction.

Data from uniaxial compression tests confirm the influence of suction on the mechanical behaviour of argillaceous rocks. The general trend is a reduction in both peak stress and Elastic Modulus along the wetting path.

\subsection{Microstructural observations}

At the end of each hydric state, a freeze-dried specimen was used to perform a microstructural analysis. The aim was to evaluate variations in the pore size distribution of the material. To do this, we use an 'AutoPore IV 9500Micrometrics Instrument Corp.' porosimeter.

Figure 12 plots pore size distribution (PSD) curves for specimens at different hydric states. The dominant pore for the undisturbed material is about $40 \mathrm{~nm}$ and exhibits some macropores. PSD curve for the higher suction $(\psi=151 \mathrm{MPa})$ indicates a dominant pore of approximately $34 \mathrm{~nm}$ while a considerable increase in the dominant pore of the PSD curve for the lower suction (7 $\mathrm{MPa})$ is observed $(180 \mathrm{~nm})$. These features are in agreement with the swelling that was detected in the material. In general, for this wetting path applied are not identifying substantial changes in the macroporosity of the material. Therefore, the main observations in its behavior may be attributed to variations in its microporosity and mesoporosity.

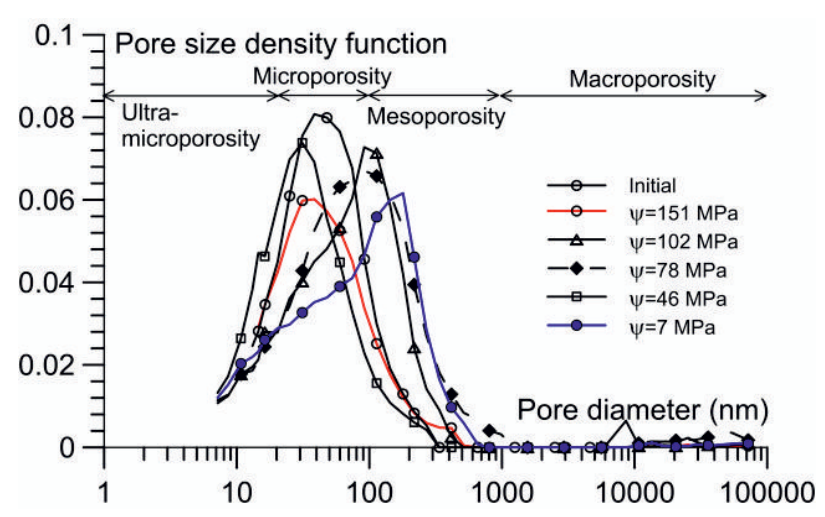

Figure 12. Variation of pore size distribution versus suction.

\section{Conclusions}

The mechanical properties of Argillaceous rocks from the Colombian Andes mountains are influenced by their moisture content which is the result of its high clay content $(53 \%)$.

As reported for other argillaceous rocks, the water retention curve represented a hysteresis loop. Dimensions of the specimens tested $(20 \mathrm{~mm}$ in diameter and $40 \mathrm{~mm}$ in height) helped to reduce the time to obtain moisture equilibrium for each hydric state. Axial and radial strains due to the wetting path imposed without mechanical load were found to be clearly anisotropic with a ratio between 2.7 and 3 .

Physical and mechanical properties of the rock are dependent on the hydric state and exhibit a non-linear relation with suction. For the compressional wave velocity, a reduction of $25 \%$ is obtained for the extreme conditions. On the other hand, peak stress displays a decrease of at least $58 \%$, while the reduction in elastic modulus is of at least $35 \%$. It is important to mention that these changes result from small variations in the water content.

Regarding microstructural observations from MIP analysis, modifications in the pore size distribution were recorded at the micro and meso scale. Therefore, the macroscopic behavior of the samples tested seems to be influenced by the number and size of the pores present in the samples. 


\section{References}

1. J. A. Pineda, E. E. Alonso, and E. Romero, Géotechnique 64, 64-82 (2014)

2. A. G. Corkum and C. D. Martin, Int. J. Rock Mech. Min. 44, 196-209 (2007)

3. A. Gens, 15th European Conference on Soil Mechanics and Geotechnical Engineering, (2013)

4. Q. T. Pham, F. Vales, L. Malinsky, D. Nguyen Minh, and H. Gharbi, Phys. Chem. Earth. 32, 646-655 (2007)

5. F. Valès, D. Nguyen Minh, H. Gharbi, and A. Rejeb, Appl. Clay. Sci., 26, 197-207 (2004)

6. D. S. Yang, M. Bornert, S. Chanchole, H. Gharbi, P. Valli, and B. Gatmiri, Int. J. Rock Mech. Min. 53, 45-55 (2012)
7. J. Espitia and B. Caicedo, 6th International Symposium on Deformation Characteristics of Geomaterials, 342-349 (2015)

8. J. Espitia and B. Caicedo, UNSAT 2014, 1597-1603 (2014)

9. I. Decagon-Devices, WP4 Dewpoint PotentiaMeter for models WP4 and WP4-T Operator's Manual Version $5,(2007)$

10. P. Delage, E. Romero, and A. Tarantino, 1st European Conference on Unsaturated Soils, (2008)

11. ASTM, E104 - 02, (2012)

12. E. Eberhardt, D. Stead, B. Stimpson, and R. S. Read, Can. Geotech J. 35, 222-233 (1998) 